\title{
Kompresör ve Türbin Palelerinin Fikstür Tasarımlarının Parametrik Analiz ve Sonlu Eleman Simülasyonları ile İncelenmesi
}

\author{
Ozgur Poyraz $^{*}$, Nurullah Yandi ${ }^{2}$ \\ 1*Eskişehir Teknik Üniversitesi, Mühendislik Fakültesi, Makine Mühendisliği Bölümü, Eskişehir, Türkiye, (ORCID: 0000-0001-9892-5738), \\ ozgurpoyraz@eskisehir.edu.tr \\ 2 Eskişehir Teknik Üniversitesi, Mühendislik Fakültesi, Makine Mühendisliği Bölümü, Eskişehir, Türkiye (ORCID: 0000-0002-0509-7513), \\ nurullahyandi@eskisehir.edu.tr
}

(1st International Conference on Applied Engineering and Natural Sciences ICAENS 2021, November 1-3, 2021)

(DOI: 10.31590 /ejosat.989033)

ATIF/REFERENCE: Poyraz, O. \& Yandi, N. (2021). Kompresör ve Türbin Palelerinin Fikstür Tasarımlarının Parametrik Analiz ve Sonlu Eleman Simülasyonları ile İncelenmesi. Avrupa Bilim ve Teknoloji Dergisi, (28), 97-105.

$\ddot{O} \mathbf{z}$

Servis ömürleri boyunca aşınma, korozyon, yorulma ve sürünme gibi pek çok sayıda olumsuz koşula maruz kalan kompresör ve türbin paleleri, ayrık tasarlanırlar ve türbin disklerine özel kök geometrileri ile bağlanırlar. Kaba haldeki paleler genellikle döküm yoluyla üretilir ve yüksek hassasiyet gerektirdiklerinden çoğunlukla sürünme ilerlemeli taşlama ile işlenir. Söz konusu palelerin gerek işleme gerekse ölçüm aşamasında sabitlenmesi için sıkça uygulanan yöntemlerden biri, pimli mekanik fikstürler ile bağlamadır. Geometrik açıdan oldukça ince ve maliyet açısından oldukça pahalı olan paleleri sabitlemek için kullanılacak pimli fikstürlerin yanlış tasarlanması ve/veya uygulanması, bu hassas parçalara zarar verebilir ve hatta 1skartaya çıkmalarına sebep olabilir. Geçmişte yapılan ve literatürde yayınlanan çalışmalar kapsamında farklı pim yerleşim ve konfigürasyonlarının ve de uygulanan bağlama kuvvetlerinin ince ve hassas olan türbin palelerindeki etkileri gözlemlenmektedir. Bununla beraber aynı araştırmacılar tarafindan aynı yaklaşımla yapılan ve söz konusu değişkenlerin sonuca tesirleri ve birbirleri ile etkileşimlerini sistematik olarak ele alan yayınlar açısından eksiklik bulunmaktadır. Yapılan bu çalışmada kompresör ve türbin palelerinin fikstür tasarımlarının sistematik analizleri gerçekleştirilmektedir. Bu kapsamda güncel uçak motorları ile uyumlu ölçülere sahip iki adet pale geometrisi oluşturulmuş ve bu paleleri sabitleyen pimlerin yerleşimleri ile bağlama kuvvetlerini dikkate alan, Taguchi yöntemi ile uyumlu deney tasarımları planlanmıştır. Deney tasarımında planlanan farklı senaryolar sonlu elemanlar yöntemi ile incelenmiş ve sonuçlar üzerinde çok değişkenli varyans analizleri (MANOVA) yapılmıştır. Yapılan farklı analizlerde ulaşılan ve birbirleri ile uyumlu olan sonuçlara göre, palelerin fikstüre sabitlenmesi sırasında uygulanan kuvvet, pale boyutu ve pale uç bölgesindeki pim yerleşiminin deformasyonlar açısından kayda değer etkisi olduğu görülmüştür.

Anahtar Kelimeler: Pale İmalatı, Fikstür Tasarımı, Sonlu Elemanlar Metodu, MANOVA

\section{Investigations on the Fixture Designs of Compressor and Turbine Blades with Parametric Analysis and Finite Element Simulations}

Compressor and turbine blades are designed separately and connected to the turbine discs with special root geometries. The raw blades are often produced by casting and machined with creep feed grinding, since they require high precision. One of the most frequently applied methods for fixing these during the machining, is fastening these with mechanical pinned fixtures. Improper design or application of these fixtures during clamping of very thin and costly blades can damage these sensitive parts and even cause them to be scrapped. Within the scope of the previous studies, the effects of different pin layouts and configurations, as well as the applied clamping forces are observed. However, the influence of these variables on the results and their interactions with each other were not researched. In this study, systematical analyzes on the fixture designs of the compressor and turbine blades are carried out. In this context, two blade geometries with dimensions compatible with current aircraft engines were created, and design of experiments compatible with the Taguchi method were planned, considering the layout of the pins and the clamping forces. Different scenarios planned in the experimental design were examined with the finite element method, and multivariate analyzes of variance (MANOVA) were performed on the result. According to the results obtained in different analyzes and which are compatible with each other, it has been observed that the force applied during the fixing of the blades to the fixture, the blade size and the pin placement in the blade tip region have significant effects on deformations.

Keywords: Blade Manufacturing, Fixture Design, Finite Element Method, MANOVA 


\section{Giriş}

Temelde içeri aldıkları havayı kompresör modülünde sıkıştıran ve yakıt karışımı ile yanma odasında yaktıktan sonra türbin modülünde genişletmek sureti ile iş elde eden uçak motorları çok yüksek dönme hızı, sıcaklık ve basınç altında çalışmaktadır [1]. Gaz akışını sağlamak için çok sayıda kanatçık geometrili parçanın kullanıldığı uçak motorlarında, söz konusu parçalar servis ömürleri boyunca aşınma, korozyon, yorulma ve sürünme gibi pek çok sayıda olumsuz koşula maruz kalmaktadır [2]. Aktarılan koşullar sebebi ile belirli periyotlarla değiştirilmesi gereken bu parçalar, değişim ve bakım kolaylığını sağlamak adına üzerinde döndükleri diskten ayrı tasarlanırlar ve pale (İng. Blade) terimi ile adlandırılırlar (Şekil 1) [3].

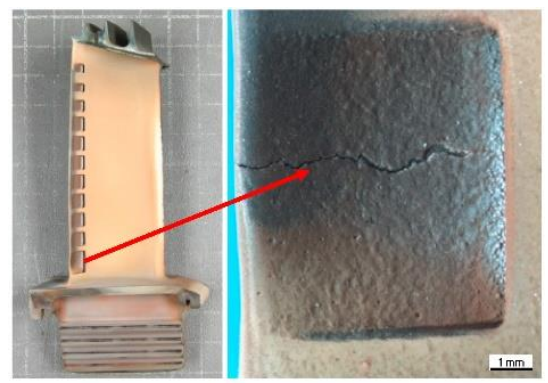

Şekil 1. Örnek bir türbin palesi ve hasar detayı [3] (Creative

Commons Attribution 4.0 Lisansı altında kullanılmıştır).

Çoğunlukla yüksek basınç kompresörü (İng. High Pressure Compressor - HPC), yüksek basınç türbini (İng. High Pressure Turbine - HPT) ve alçak basınç türbini (İng. Low Pressure Turbine - LPT) modüllerinde kullanılan paleler türbin disklerine özel kök geometrileri ile bağlanırlar [4]. Yarı mamul olarak tek kristalli hassas döküm veya yönlendirilmiş katılaşma ile döküm yöntemleri ile üretilen palelerin kök geometrileri, daha sonra sürünme ilerlemeli taşlama (İng. Creep Feed Grinding - CFG), form frezeleme veya tel erozyon (İng. Wire Electrode Discharge Machining - WEDM) ile hassas ölçüye getirilmektedir (Şekil 2) [5]. Burada sözü edilen hassasiyet, pale köklerinin disklerle eşleşen yüzeyleri için parça referans noktasına kıyasla toplamda $\pm 0.010 \mathrm{~mm}$ tolerans seviyeleri ile ifade edilmektedir [6].
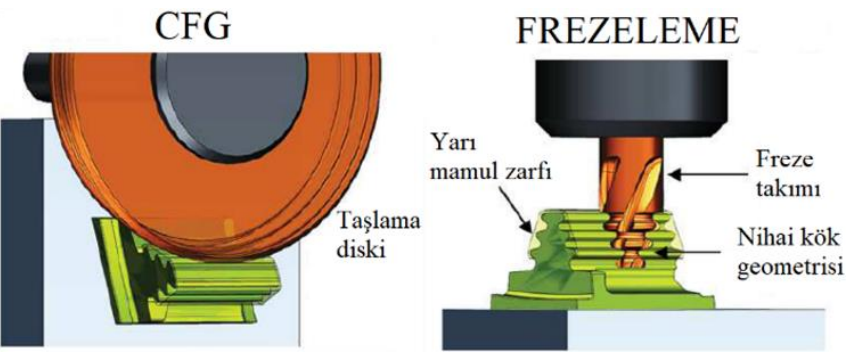

Şekil 2. Pale köklerinin CFG ve frezeleme ile işlenmesi [5].

\subsection{Fikstür Tasarımları}

İstenen hassasiyetin sağlanması için seçilen işleme yöntemine ait proses parametrelerinin uygun belirlenmesine ek olarak parçanın hareket etmeyecek ve/veya deforme olmayacak şekilde sabitlenmesi gerekmektedir [7]. Bunlara ilaveten kullanılan fikstürün üretkenlik, takım ömrü ve az tezgâh hareketi ve buna bağlı az işleme süreleri gibi hususlara katkıda bulunması beklenmektedir [8]. Söz konusu olan parçalar kompresör ve türbin paleleri gibi ince cidarlı geometriler olduğunda bu durum daha fazla önem kazanmaktadır. Kompresör ve türbin palelerinin işlenmesi için kullanılan fikstürler iki grupta toplanabilir ve bunlar sırası ile kapsül içi fikstürler ile mekanik pimli fikstürlerdir. Kapsül içi fikstürlerde, sınırları belirli bir hacim içine doldurulan düşük ergime noktalı bir alaşım (kalay-bizmut) havuzuna pale yerleştirilir ve alaşım tekrar katılaştığında pale sabitlenmiş olur [9]. Bu yöntem her ne kadar titreşim sönümleme gibi bazı avantajlar sunsa da ergitme ve katılaşmanın uzun sürmesi, hassas dökümle üretilmiş pale yüzeyinde malzeme kalıntısı bırakma ve kalite kusuru oluşturma risklerine sahip olması, ve de iş güvenliği-çevre konularında ek önlem ve maliyet gerektirmesi sebepleri ile daha az tercih edilmektedir [9], [10].

Mekanik pimli fikstürler, kapsül içi fikstürlerin dezavantajlarından kaçınmak için tercih edilebilecek ikinci gruptur. Mekanik pimli fikstürler temelde pale yüzeyine teğet olarak dokunan küresel uçlu pimlerin belirli bir bağlama kuvveti ile parçaları sabitlediği düzeneklerdir. Bu fikstürler uluslararası enstitüler ve kurumlar tarafından yayınlanan iyi uygulama kılavuzlarında, ürünlerin ölçüm ve diğer sebeplerle konumlarının tam olarak kısıtlanabilmesi ve serbestlik derecesinin sıfırlanması için gerekli olan 3-2-1 kuralını pimleri bu doğrultuda gruplandırarak sağlarlar [11], [12]. 3-2-1 prensibi bir düzlem, bir doğrultu ve bir konum belirtmektedir, ve palelere uygulandığ takdirde 3 nokta akış yüzeyi üzerinden, 2 nokta hücum veya firar kenarlarından ve 1 nokta da platform veya uç bölgelerinden seçilebilir. Şekil 3'te endüstri ve akademiden aktarılan prensibin uygulandığı fikstür tasarımları görülmektedir.

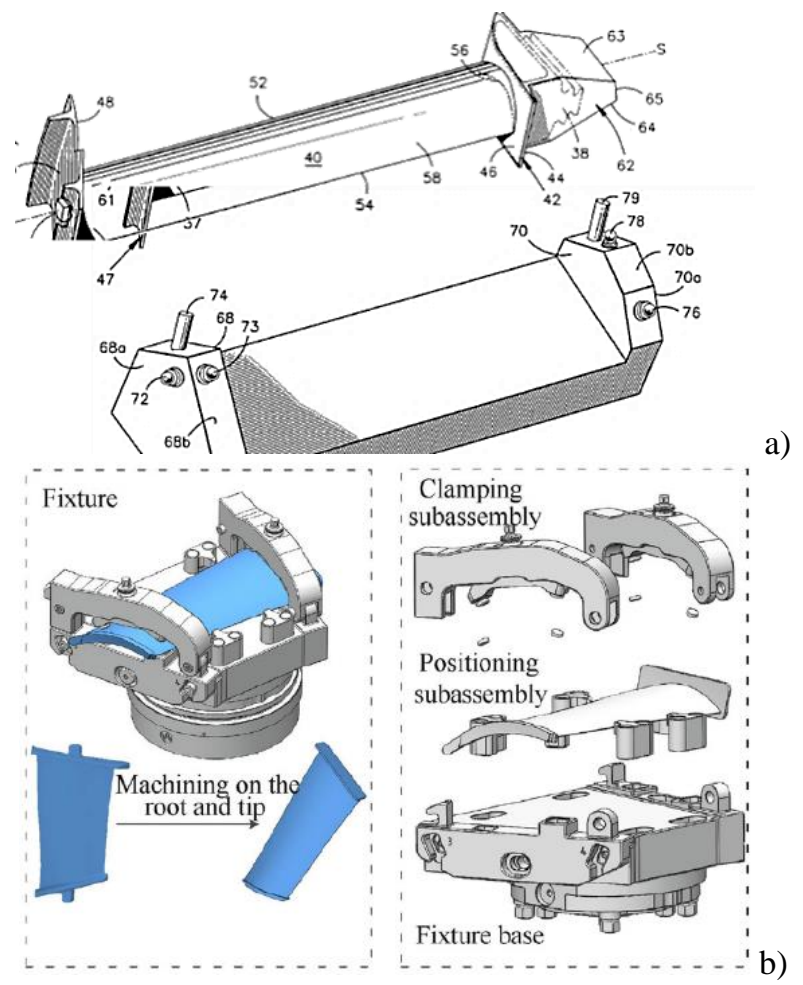

Şekil 3. Örnek mekanik pimli fikstür tasarımları: a) [10], b) [13] (Creative Commons Attribution 4.0 Lisansı altında kullanılmıştır).

\subsection{Karşılaşılan Zorluklar ve Fikstürlerin Analizi}

Mekanik pimli fikstürler her ne kadar kapsül içi fikstürlerin yarattığı dezavantajları giderse de bunları kullanırken dikkat edilmesi gereken başka hususlar bulunmaktadır. Bu kapsamda pimlerin, palenin yüzeyleriyle tam olarak nasıl konumlandırılacağı, ince cidarlı parçanın izin verilen deformasyonlar dahilinde nasıl sıkıca tutulacağı ve palenin 
yüksek tolerans isterlerini sağlarken nasıl etkin bir şekilde işleneceği gibi bazı zorlukların aşılması gerekmektedir. Sıralanan zorlukları aşabilmek için deneysel testler tek karşı önlem olarak kullanıldığında maliyetli olabilir. $\mathrm{Bu}$ bağlamda, deneysel maliyetleri düşürmek için Sonlu Elemanlar Yöntemi (İng. Finite Element Method- FEM) ile analiz ve simülasyonlar yapılabilir. Bununla birlikte, FEM analiz ve simülasyonlarının güvenirliği için doğru girdilerin sağlanması ve sonuçların bilinçli bir şekilde yorumlanması önemlidir.

FEM ile gerçekleştirilen analiz ve simülasyonlarda en sık irdelenen durumların başında yapısal deformasyonlar gelmektedir. $\mathrm{Bu}$ doğrultuda palelerin mekanik pimli fikstürlere sabitlenmesi ve/veya sonrasında işlenmesi sırasında ortaya çıkan kuvvetlerin parçada oluşturduğu deformasyon seviyeleri araştırılmaktadır. Bunlar araştırılırken malzemelerin mekanik (elastik ve/veya plastik) özelliklerine ihtiyaç duyulmaktadır [9], [13], [14]. Malzeme özelliklerine ek olarak dikkat edilmesi gereken diğer hususlar arasında sınır koşulları (İng. Boundary Conditions - BC) ve ağ elemanlarının (İng. Mesh Elements) tipleri ile boyutları bulunmaktadır. Literatürde yapılan çalışmalar incelendiğinde sıralanan hususlar arasından ağ elemanları hakkında farklı araştırmacıların benzer yorumlarına ulaşılmaktadır [9], [13], [14], [15]. Buna göre serbest yüzey geometrisine sahip palelerin FEM ile analizi için farklı geometrilere adaptasyon kolaylığı olan dört yüzlü (İng. Tetrahedral) elemanların kullanımın faydalı olduğu raporlanmaktadır. Buna ek olarak eleman boyutlarının doğru seçim gerekliliği de vurgulanmaktadır [14], [16]. A $\breve{g}$ elemanları ile ilgili ulaşılan ortak yargı yazık ki sınır koşulları için geçerli değildir. $\mathrm{Bu}$ duruma bir örnek vermek gerekirse bağlama kuvvetlerinin farklı araştırmacılar tarafından çok farklı seviyede kullanıldığ mevcuttur (Tablo 1). Bu farklılıkların sebepleri arasında parça ve fikstür malzemesi, işleme yöntemi, işleme parametreleri gibi çok sayıda neden sayılabilir.

Tablo 1. Mekanik pimli fikstürlere uygulanan kuvvetler.

\begin{tabular}{|c|c|c|c|}
\hline $\begin{array}{c}\text { Referans } \\
\text { No. }\end{array}$ & $\begin{array}{c}\text { Bağlama } \\
\text { Kuvveti (N) }\end{array}$ & $\begin{array}{c}\text { Referans } \\
\text { No. }\end{array}$ & $\begin{array}{c}\text { Kesme } \\
\text { Kuvveti (N) }\end{array}$ \\
\hline$[9]$ & $100-400$ & {$[7]$} & 1000 \\
\hline$[15]$ & 1445 & {$[9]$} & $80-450$ \\
\hline$[17]$ & 584 & {$[14]$} & $1600-1800$ \\
\hline$[18]$ & $500-3000$ & {$[15]$} & 3818 \\
\hline$[19]$ & 110 & {$[17]$} & $332-827$ \\
\hline$[20]$ & 200 & {$[22]$} & $250-600$ \\
\hline$[21]$ & 673 & {$[23]$} & 2800 \\
\hline- & - & {$[24]$} & $100-1300$ \\
\hline
\end{tabular}

Farklılıkların görüldüğü diğer bir alan da pimlerin yerleşimleridir. Bu alanda çoğu araştırmacı genel olarak 3-2-1 kuralına uyum sağlasa da, akış yüzeyi üzerindeki ana bağlama fonksiyonunu yerine getiren 3 pimin yerleşimini farklı yapmaktadır [8], [10], [15], [18]. Burada bazı araştırmacılar akış yüzeyindeki pimleri eşit aralıklarla planlarken, diğerleri 2 pimi pale ucuna diğer 1 pimi ise pale platformuna yakın konumlandirabilmektedir [8], [10], [15], [18].

\subsection{Yenilikçi Yön}

Gerek tasarımlar gerekse analizlerin sınır koşullarındaki bu farklılık her yeni pale tasarımı için çok sayıda deneme yanılma ihtiyacı doğurmaktadır. Ortalama bir ticari ve/veya askeri uçak motorunda kompresör ve türbin modüllerindeki toplam kademe sayısının ve buna bağlı olarak da pale tasarımlarının onlarca çeşitte olduğu düşünüldüğünde, maliyetleri de yüksek olan bu parçalar için uygulanabilir bir durum sağlanamamaktadır. Bu sebeple aynı araştırmacı tarafından aynı inceleme yöntemi ile farklı tasarım, yerleşim ve bağlama kuvvetlerinin etkisinin irdelenmesine ihtiyaç duyulmaktadır.

$\mathrm{Bu}$ makalede güncel ticari uçak motorları için ölçüleri uyumlu iki farklı pale geometrisi oluşturulmuştur. Inconel 718 malzeme özellikleri üzerinden değerlendirilen paleler için hassasiyet analizleri ile uygun sonlu eleman boyutları belirlenmiştir. Daha sonra literatürün genelini temsil edecek farklı pim yerleşimleri pale geometrisinin sınırlarına göre oluşturulmuş ve bunlara da farklı seviyelerde bağlama kuvvetleri uygulanmıştır. Oluşturulan farklı senaryolar için deney tasarımı yapılmış ve L18 $\left(2^{1} \times 3^{7}\right)$ ortogonal dizisine uyarlanmıştır. Ortogonal dizideki senaryolara göre gerçekleştirilen sonlu elemanlar yöntemi simülasyonlarının sonuçları çok değişkenli varyans analizi (MANOVA) tekniği ile değerlendirilmiş ve tartışılmıştır.

\section{Materyal ve Metot}

\subsection{Pale Geometrilerinin Oluşturulması}

$\mathrm{Bu}$ çalışmada irdelenen, analiz ve simülasyonları gerçekleştirilen pale geometrilerinin güncel uçak motorlarını yansıtması hedeflenmiştir. $\mathrm{Bu}$ doğrultuda literatür araştırması yapılmış ve güncellik hedefini sağlarken geometrilerin oluşturulması için gerekli ölçüleri de içeren bir kaynak tespit edilmiştir [25]. Tespit edilen kaynaktaki uçak motoru turbofan tipinde olup, $101.46 \mathrm{kN}$ itki sağlayan Fransız-Rus ortak yapımı PowerJet SaM146 modelidir [25]. Pale geometrileri oluşturulurken ilgili kaynakta gaz akış yolu için verilen kanatçık yükseklikleri, kanatçık genişlikleri, hücum kenar yarıçapı, firar kenar yarıçapı ve burulma açısına ait ortalama değerler kullanılmış, kök kısmı ise işleme öncesindeki bir dolu geometri ile temsil edilmiştir [25]. Pale geometrileri Siemens NX 12 yazılımında modellenerek oluşturulmuştur. Pale geometrisi için temel terimler Şekil 4'te ve oluşturulan palelerin ölçüleri Tablo 2'de verilmektedir.

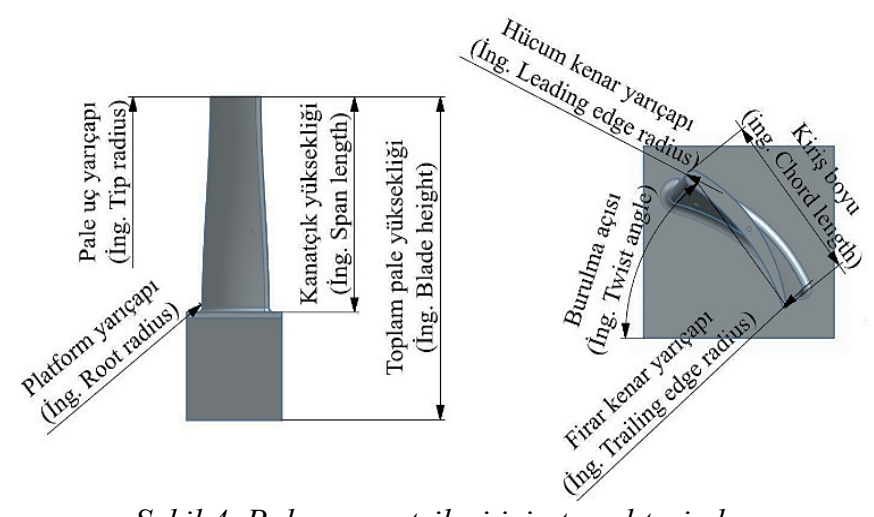

Şekil 4. Pale geometrileri için temel terimler 
Tablo 2. Pale ölçüleri.

\begin{tabular}{|c|c|c|}
\hline Ölçü Adı & $\begin{array}{c}\text { Pale 1 } \\
\text { Kısa Pale }\end{array}$ & $\begin{array}{c}\text { Pale 2 } \\
\text { Uzun Pale }\end{array}$ \\
\hline Pale uç yarıçap1 & $1560(\mathrm{~mm})$ & $1776(\mathrm{~mm})$ \\
\hline Kanatçı yüksekliği & $90(\mathrm{~mm})$ & $125(\mathrm{~mm})$ \\
\hline Toplam pale yüksekliği & $135(\mathrm{~mm})$ & $170(\mathrm{~mm})$ \\
\hline Platform yarıçapı & $2(\mathrm{~mm})$ & $2(\mathrm{~mm})$ \\
\hline Ortalama kiriş boyu & $35(\mathrm{~mm})$ & $35(\mathrm{~mm})$ \\
\hline Hücum kenar yarıçapı & $1.6(\mathrm{~mm})$ & $1.6(\mathrm{~mm})$ \\
\hline Firar kenar yarıçapı & $0.4(\mathrm{~mm})$ & $0.4(\mathrm{~mm})$ \\
\hline Ortalama burulma açısı & $50^{\circ}$ & $50^{\circ}$ \\
\hline
\end{tabular}

\subsection{Deney Tasarımı}

$\mathrm{Bu}$ makale kapsamında literatürde eksikliği bulunan ve değiştirildiği takdirde sonuca etkisi irdelenmemiş olan mekanik pimli fikstürler için yerleşim senaryoları ile kesme kuvvetlerinin anlaşılmasına yönelik bir deney tasarımı (İng. Design of Experiment - DoE) planlanmıştır.

$\mathrm{Bu}$ amaçla akış yüzeyine temas edecek pimlerin başlangıç konumları ortalama olarak alınmış ve ilk aşamada 2 pimin akış yüzeyi üzerinde firar kenarına yakın bir bölgede, diğer 1 pimin ise akış yüzeyi üzerinde hücum kenarına yakın bir bölgede olduğu kabul edilmiştir. Sonrasında söz konusu üç pimin yerleri bulundukları bölgede kanatçık yüksekliği ve kiriş doğrultusunda sistematik olarak değiştirilmiştir. Değişim basamakları, önerilen yöntemin başka boyutlu palelere de uygulanabilmesi için \% (oran) olarak girilmiştir. Buna göre her üç pimin de yükseklik veya genişlik doğrultusunda kendine yakın kenara olan uzaklığının o kesitteki toplam yükseklik veya genişliğe oranı esas alınmıştır. Pimlerin yerleşimine ek olarak farklı pale boyu ve farklı bağlama kuvveti seviyeleri de değişken olarak belirlenmiştir.

Şekil 5'te pim yerleşimlerinde esas alınan mesafe oranları şematik olarak gösterilmektedir. Tablo 3'te deney senaryo/sembolleri, kontrol faktörleri ve seviyeleri sunulmaktadır. Tablo 4'te deney tasarımlarında esas alınan L18 $\left(2^{1} \times 3^{7}\right)$ ortogonal dizisi verilmektedir.

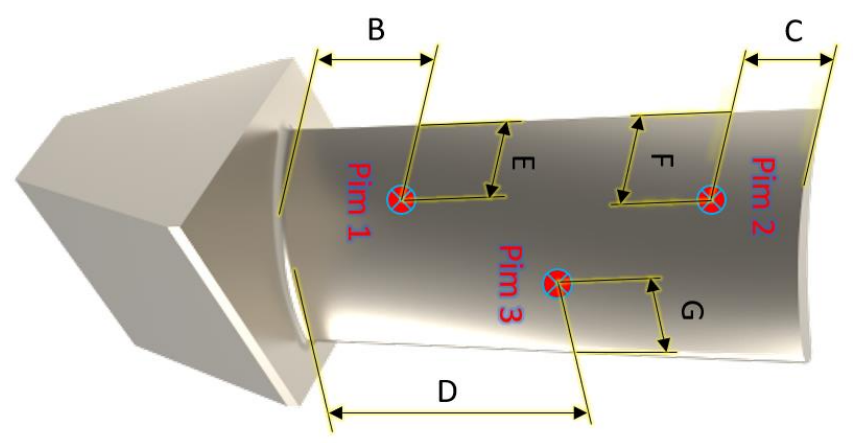

Şekil 5. Pale geometrisi üzerinde pim yerleşimleri.

Tablo 3. Deney tasarımı için kontrol faktörleri ve seviyeleri.

\begin{tabular}{|c|l|c|c|c|c|}
\hline \multirow{2}{*}{ Sembol } & \multicolumn{1}{|c|}{ Kontrol Faktörüi } & \multirow{2}{*}{ Birim } & \multicolumn{3}{|c|}{ Seviye } \\
\cline { 3 - 6 } & & - & $\mathbf{1}$ & $\mathbf{2}$ & $\mathbf{3}$ \\
\hline A & Pale boyu & Uzun & \\
\hline B & 1. Pimin kendine en yakın pale sınırına uzaklığının pale yüksekliğine oranı & $\%$ & 12.5 & 25 & 37.5 \\
\hline C & 2. Pimin kendine en yakın pale sınıına uzaklığının pale yüksekliğine oranı & $\%$ & 12.5 & 25 & 37.5 \\
\hline D & 3. Pimin kendine en yakın pale sınırına uzaklığının pale yüksekliğine oranı & $\%$ & 37.5 & 50 & 62.5 \\
\hline E & $\begin{array}{l}\text { 1. Pimin kendine en yakın pale sınırına uzaklığının pale genişliğine (kiriş boyu) } \\
\text { oranı }\end{array}$ & $\%$ & 12.5 & 25 & 37.5 \\
\hline F & $\begin{array}{l}\text { 2. Pimin kendine en yakın pale sınırına uzaklığının pale genişliğine (kiriş boyu) } \\
\text { oranı }\end{array}$ & $\%$ & 12.5 & 25 & 37.5 \\
\hline G & $\begin{array}{l}\text { 3. Pimin kendine en yakın pale sınırına uzaklığının pale genişliğine (kiriş boyu) } \\
\text { oranı }\end{array}$ & $\%$ & 12.5 & 25 & 37.5 \\
\hline H & Bağlama kuvveti & $\mathrm{N}$ & 125 & 250 & 375 \\
\hline
\end{tabular}

\subsection{Sonlu Elemanlar Yöntemi ile Analizler}

Literatürde yapılan çalışmalarda fikstürlerin bağlama kuvvetlerinin belirlenmesi için yapılan bazı statik ve mukavemet hesaplamaları bulunmaktadır [7], [17], [19]. Bu kapsamda basit geometrili (örneğin prizmatik) cisimlerin işlenmesinde $\mathrm{X}, \mathrm{Y}$ ve $\mathrm{Z}$ eksenlerindeki kuvvetlerin bileşkeleri ile yine aynı yönler etrafindaki döner eksenlerde oluşan momentlerin bileşkelerinin 0 'a eşitlenmesi yaygın bir yöntemdir. Bu yöntemde oluşan işleme kuvveti statik sürtünme katsayısına bölünmekte ve tasarımcı tarafından belirlenen bir güvenlik faktörü ile çarpılmaktadır. Elde edilen bu değer ve denge denklemleri sayesinde her pimin ihtiyaç duyduğu bağlama kuvveti ortaya çıkmaktadır.

Pale parçaları ise serbest yüzeyli karmaşık geometrilere sahip oldukları için bu yapılamamaktadır. Bunun yerine literatürde uygulanan farklı sonlu elemanlar yöntemi esaslı hesaplamalar arasında pimleri modelleyerek (rijit veya esnek) pimden dolaylı şekilde yüzeye kuvvet etki ettirmek, yüzeye yer değiştirme tanımlamak veya direk olarak yüzeydeki bağlantı noktalarına kuvvet uygulayarak sonuçları elde etmek bulunmaktadır [14], [17], [19].

$\mathrm{Bu}$ çalışmada da bağlama kuvvetlerini direk yüzeye uygulamak ve bu sayede temas problemlerinin hesaplaması sebebi ile ortaya çıkabilecek uzun çözüm sürelerinden tasarruf sağlamak hedeflenmiştir. Genellikle küresel olarak tasarlanan ve pale yüzeyine teğet dokunan pimler için noktadan kuvvet uygulamak tekillik oluşturabileceği için pimlerin temas ettiği yerler $0.5 \mathrm{~mm}$ çapında daireler ile temsil edilmiştir. Bu daireler için öncelikle pimlerin deney tasarımında verilen faktörlere göre merkez konumları belirlenmiştir. $\mathrm{Bu}$ merkez konumlarından 
geçen ve o noktalarda yüzey normaline dik olan düzlemler oluşturularak, daireler bu düzlemlerin üzerinde çizilmiştir. Son aşamada yüzeyler bu daireler ile bölünerek sınır koşulları pimleri temsil eden yüzeylerden uygulanmıştır (Şekil 6-a). 3-2-1 yönteminde kullanılan ve pale kenarları ile platforma denk gelen diğer pimler için herhangi bir kuvvet uygulanmamış, yalnızca o pimlerin fikstür tasarım prensibine göre yapacağı durdurucu etki, ilgili yönlerdeki yer değiştirme izinleri 0 girilerek yansıtılmıştır. Uçak motorlarında ve palelerde kullanım oranı yüksek olduğu için seçilen Inconel 718 parça malzemesinin sonlu elemanlar yöntemi ile analizlerde esas alınan özellikleri Tablo 5'te verilmektedir. Verilen malzeme özellikleri Ansys Workbench malzeme kütüphanesinden alınmıştır.

Tablo 4. L18 $\left(2^{1} \times 3^{7}\right)$ ortogonal dizisi.

\begin{tabular}{|c|c|c|c|c|c|c|c|c|}
\hline & \multicolumn{7}{|c|}{ Kontrol Faktörleri } \\
\hline $\begin{array}{c}\text { Deney } \\
\text { No. }\end{array}$ & A & B & C & D & E & F & G & H \\
\hline $\mathbf{1}$ & 1 & 1 & 1 & 1 & 1 & 1 & 1 & 1 \\
\hline $\mathbf{2}$ & 1 & 1 & 2 & 2 & 2 & 2 & 2 & 2 \\
\hline $\mathbf{3}$ & 1 & 1 & 3 & 3 & 3 & 3 & 3 & 3 \\
\hline $\mathbf{4}$ & 1 & 2 & 1 & 1 & 2 & 2 & 3 & 3 \\
\hline $\mathbf{5}$ & 1 & 2 & 2 & 2 & 3 & 3 & 1 & 1 \\
\hline $\mathbf{6}$ & 1 & 2 & 3 & 3 & 1 & 1 & 2 & 2 \\
\hline $\mathbf{7}$ & 1 & 3 & 1 & 2 & 1 & 3 & 2 & 3 \\
\hline $\mathbf{8}$ & 1 & 3 & 2 & 3 & 2 & 1 & 3 & 1 \\
\hline $\mathbf{9}$ & 1 & 3 & 3 & 1 & 3 & 2 & 1 & 2 \\
\hline $\mathbf{1 0}$ & 2 & 1 & 1 & 3 & 3 & 2 & 2 & 1 \\
\hline $\mathbf{1 1}$ & 2 & 1 & 2 & 1 & 1 & 3 & 3 & 2 \\
\hline $\mathbf{1 2}$ & 2 & 1 & 3 & 2 & 2 & 1 & 1 & 3 \\
\hline $\mathbf{1 3}$ & 2 & 2 & 1 & 2 & 3 & 1 & 3 & 2 \\
\hline $\mathbf{1 4}$ & 2 & 2 & 2 & 3 & 1 & 2 & 1 & 3 \\
\hline $\mathbf{1 5}$ & 2 & 2 & 3 & 1 & 2 & 3 & 2 & 1 \\
\hline $\mathbf{1 6}$ & 2 & 3 & 1 & 3 & 2 & 3 & 1 & 2 \\
\hline $\mathbf{1 7}$ & 2 & 3 & 2 & 1 & 3 & 1 & 2 & 3 \\
\hline $\mathbf{1 8}$ & 2 & 3 & 3 & 2 & 1 & 2 & 3 & 1 \\
\hline
\end{tabular}

Tablo 5. Inconel 718 malzeme özellikleri.

\begin{tabular}{|c|c|c|c|c|}
\hline $\begin{array}{c}\text { Sıcaklık } \\
\left({ }^{\circ} \mathbf{C}\right)\end{array}$ & $\begin{array}{c}\text { Elastik } \\
\text { Modül } \\
(\mathbf{M P a})\end{array}$ & $\begin{array}{c}\text { Poisson } \\
\text { Oranı } \\
(-)\end{array}$ & $\begin{array}{c}\text { Kayma } \\
\text { Modülü } \\
(\mathbf{M P a})\end{array}$ & $\begin{array}{c}\text { Akma } \\
\text { Dayanımı } \\
(\mathbf{M P a})\end{array}$ \\
\hline 21 & $2.05 \mathrm{e}+05$ & 0.28 & 78846 & 648 \\
\hline 537 & $1.52 \mathrm{e}+05$ & 0.3 & 59375 & 558 \\
\hline 815 & $1.1 \mathrm{e}+05$ & 0.323 & 41572 & 338 \\
\hline 982 & 55000 & 0.368 & 20102 & 90 \\
\hline 1093 & 34000 & 0.4 & 12143 & 30 \\
\hline
\end{tabular}

Analizlerin gerçekleştirilmesinin ilk aşamasında ăg elemanları için hassasiyet çalışmaları yapılmış ve doğru eleman tipi ile doğru eleman boyutu bulunması hedeflenmiştir. Eleman tipi olarak geçmiş literatürdeki araştırmacıların, geometrik adaptasyon kabiliyeti sebebi ile önerdiği dört yüzlü elemanlar seçilmiştir. Eleman boyutu olarak değişken boyut seçilmiştir ve bu sayede geometrik unsurların en geniş olduğu yerde seçilen başlangıç boyutu sağlanmak üzere, daha detay unsurlara yaklaşıldıkça boyutun adaptif olarak küçülmesi sağlanmıştır (Şekil 6-b).
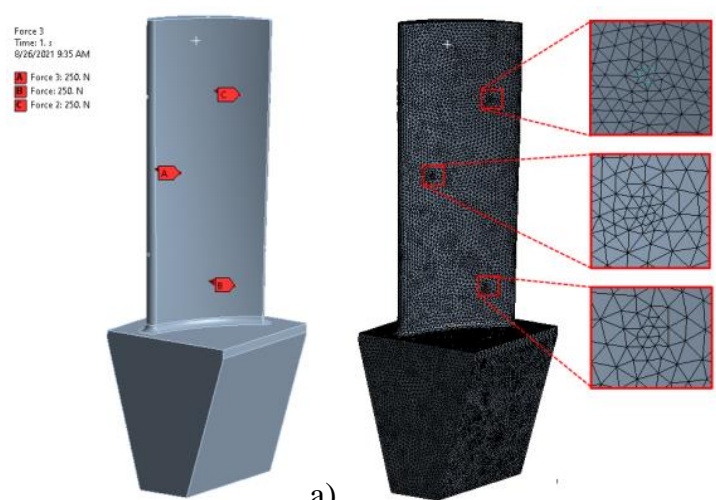

a)

b)

Şekil 6. a) Sınır koşulları, b) Değişken ă̆ eleman örgüsü.

Elemanlar için seçilen başlangıç boyutları sırası ile $8 \mathrm{~mm}, 4$ $\mathrm{mm}, 2 \mathrm{mmm}, 1 \mathrm{~mm}$ ve $0.5 \mathrm{~mm}$ değerindedir. Aktarılan malzeme özellikleri, sınır şartları ve ağ eleman boyut seçenekleri kullanılarak analizler yapılmıştır. Analizlerin gerçekleştirildiği iş istasyonu bilgisayar her biri $3.40 \mathrm{GHz}$ hızda 8 çekirdekli bir işlemciye, 96 GB rastgele erişim belleğine ve kendine ayrılmış 8 GB bellekli bir grafik işlemci ünitesine sahiptir.

Yapılan analizlerde elde edilen eşdeğer gerilme değerleri, toplam deformasyon değerleri ve bilgisayar çözüm süreleri için optimum nokta tespit edilmiştir. Buna göre başlangıç ağ eleman boyutları $8 \mathrm{~mm}$ değerinden $1 \mathrm{~mm}$ değerine düşene kadar eşdeğer gerilme ve toplam deformasyonda kayda değer bir değişim olmaktadır. $\mathrm{Bu}$ boyuttan sonra ise sonuçlarda gözlemlenen değişim minör seviyededir (Şekil 7).

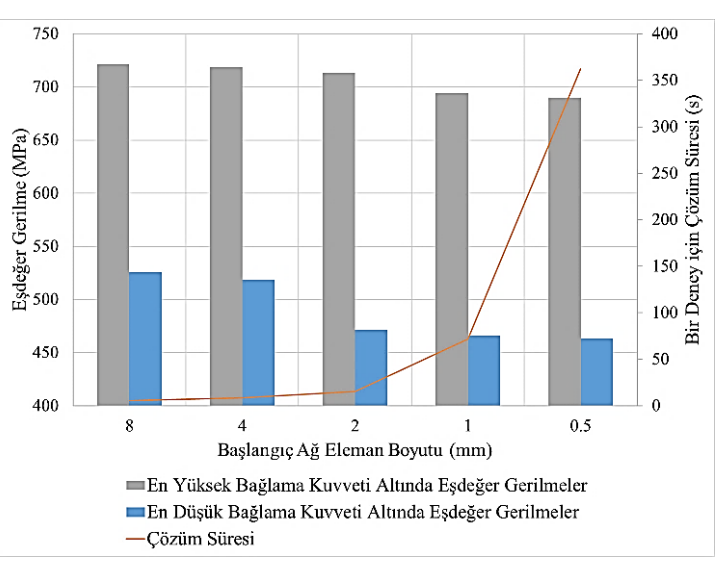

Şekil 7. Ăg elemanı boyutları için hassasiyet analizleri.

$\mathrm{Bu}$ sebeple başlangıç ağ eleman boyutu olarak $1 \mathrm{~mm}$ seçilmiştir. $\mathrm{Bu}$ seçim ağ elemanı kalite istatistikleri ile de desteklenmiştir. Ansys Workbench yazılımında gerçekleştirilen istatistiklere göre ortalama sayısı 660000 adet olan elemanların $\% 75$ 'inden daha fazlası için kalite ve farklı eleman kenarları için en/boy oranı 0.9 'un üzerindedir. En yüksek değerin 1.0 olduğu göz önüne alınarak kabul edilebilir bir seviyede olduğu teyit edilmiştir. Atanan malzeme özellikleri, uygulanan sınır koşulları ve hassasiyet analizleri sonucunda belirlenen ăg eleman boyutlarına uygun olarak Tablo 4 'teki tüm kombinasyonlar için sonlu eleman analizleri gerçekleştirilmiştir.

\section{Bulgular}

Sonlu elemanlar yöntemi ile Tablo 4'e göre gerçekleştirilen analizlerin sonuçları Tablo 6'da verilmektedir. Tabloda paleler üzerindeki deformasyon dağılım grafiği ile deney numarası, en fazla deformasyon değeri ve en fazla gerilme değeri sunulmuştur. 
Tablo 6. 18 adet deney için sonlu elemanlar yöntemi ile analiz sonuçları.

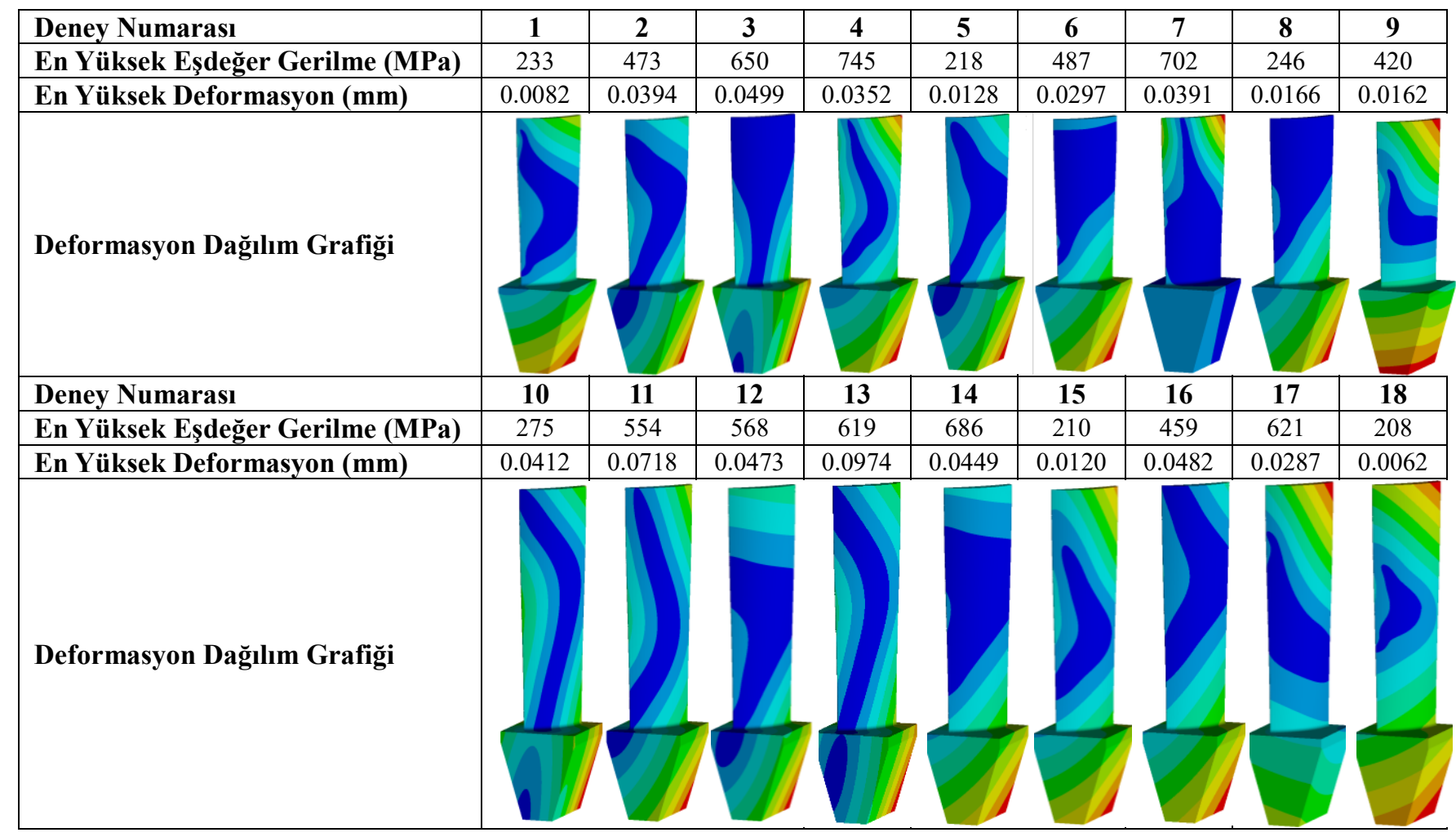

Tablo 3'te verilen kontrol faktörleri ve seviyelerinin esas alındığı, Tablo 4'te verilen ortogonal diziye uygun şekilde gerçekleştirilen ve Tablo 6'da sonlu elemanlar analizi ile elde edilen en yüksek deformasyon sonuçlarının sunulduğu deney tasarımı için Minitab yazılımında Taguchi ve çok değişkenli varyans analizleri (MANOVA) gerçekleştirilmiştir. Analizlerde pale geneli için verilen en yüksek deformasyon değerine ek olarak pale kökü ve pale ucunda ulaşlan en yüksek deformasyon değerleri de genel durumun daha iyi irdelenebilmesi için ortalamalara dahil edilmiştir.

Deneylerden elde edilen uzaklaşma ve verim sonuçları sinyal/gürültü oranına (İng. Signal/Noise - $\mathrm{S} / \mathrm{N}$ ) çevrilerek değerlendirme yapılmıştır. $\mathrm{S} / \mathrm{N}$ oranındaki $\mathrm{S}$ sinyal faktörünü, $\mathrm{N}$ ise gürültü faktörünü ifade etmektedir. Sinyal faktörü sistemden alınan gerçek değeri, gürültü faktörü ise deney tasarımına katılamayan fakat deney sonucuna etki eden faktörleri ifade etmektedir. Tablo 7'de kontrol faktörlerinin $\mathrm{S} / \mathrm{N}$ cinsinden etkinlik değeri verilmektedir. Burada kullanılan model "nominal en iyi” kabulü yapan modeldir $\left(10 \times \log 10\left(\mathrm{Ybar}^{\wedge} 2 / \mathrm{s}^{\wedge} 2\right)\right.$.

Tablo 7. Kontrol faktörlerinin S/N cinsinden etkinlik değeri.

\begin{tabular}{|l|c|c|c|c|c|c|c|c|}
\hline Seviye & A & B & C & D & E & F & G & H \\
\hline $\mathbf{1}$ & 15.3 & 14.9 & 12.6 & 20.0 & 18.0 & 17.0 & 17.4 & 16.9 \\
\hline $\mathbf{2}$ & 16.2 & 15.2 & 14.4 & 12.9 & 16.1 & 19.3 & 13.8 & 16.9 \\
\hline $\mathbf{3}$ & & 17.1 & 20.2 & 14.2 & 13.1 & 10.9 & 16.0 & 13.4 \\
\hline Fark & 0.9 & 2.2 & 7.7 & 7.1 & 4.9 & 8.4 & 3.6 & 3.5 \\
\hline
\end{tabular}

Taguchi yöntemini esas alan analizlerden elde edilen diğer bir bulgu da kontrol faktörlerinin ortalamalarının etkinlik değeridir.
Bu da Tablo 8'de gösterilmektedir. Tabloya ek olarak farklı kontrol faktörlerinin farklı seviyelerindeki eğilimlerinin daha iyi anlaşılabilmesi için kontrol faktörlerinin ortalama etkinlik değeri Şekil 8'de grafik halinde sunulmuştur.

Araştırma kapsamında gerçekleştirilen son değerlendirme çok değişkenli varyans analizleri (MANOVA) ile yapılmıştır. Minitab yazılımı ile gerçekleştirilen analizlerde "Pillai kriteri" kullanılarak F ve P değerleri hesaplanmıştır. MANOVA analizleri ile farklı faktörler için farklı modellerle gerçekleştirilen hesaplama sonuçları Tablo 9'da verilmektedir.

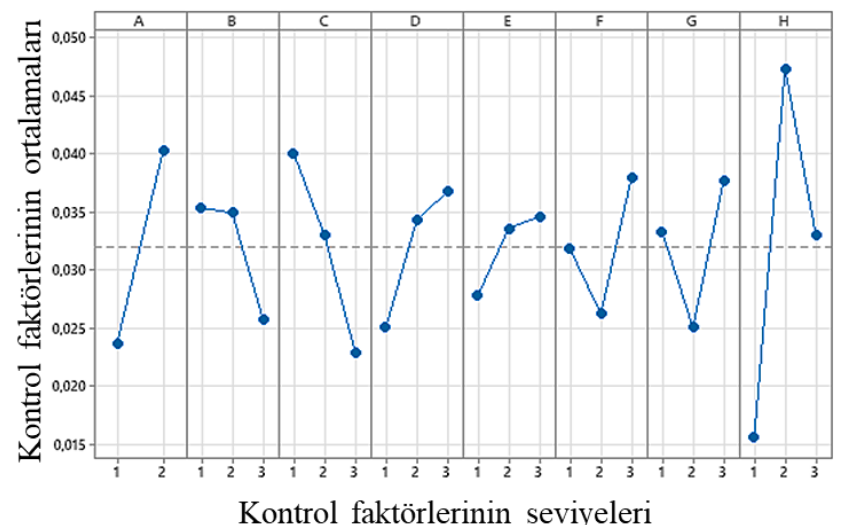

Şekil 8. Kontrol faktörlerinin etkisi.

Gerek Taguchi yöntemini esas alan gerekse MANOVA analizleri ile ilgili detaylı bilgiler ve yorumlar, tartışmalar bölümünde sunulmaktadır. 
European Journal of Science and Technology

Tablo 8. Kontrol faktörlerinin ortalamalarının etkinlik değeri.

\begin{tabular}{|c|c|c|c|c|c|c|c|c|}
\hline Seviye & A & B & C & D & E & F & G & H \\
\hline $\mathbf{1}$ & 0.02376 & 0.03536 & 0.04007 & 0.02507 & 0.02786 & 0.03181 & 0.03331 & 0.01571 \\
\hline $\mathbf{2}$ & 0.04030 & 0.03492 & 0.03302 & 0.03426 & 0.03361 & 0.02629 & 0.02509 & 0.04729 \\
\hline $\mathbf{3}$ & - & 0.02580 & 0.02299 & 0.03675 & 0.03461 & 0.03798 & 0.03768 & 0.03308 \\
\hline Fark & 0.01654 & 0.00955 & 0.01708 & 0.01167 & 0.00675 & 0.01169 & 0.01259 & 0.03158 \\
\hline
\end{tabular}

Tablo 9. MANOVA analizleri sonucunda ulaşılan bulgular.

\begin{tabular}{|c|c|c|c|c|c|c|c|c|c|c|c|c|c|c|}
\hline Kontrol Faktörü & \multicolumn{2}{|c|}{ B } & \multicolumn{2}{|c|}{ C } & \multicolumn{2}{|c|}{ D } & \multicolumn{2}{|c|}{$\mathbf{E}$} & \multicolumn{2}{|c|}{$\mathbf{F}$} & \multicolumn{2}{|c|}{ G } & \multicolumn{2}{|c|}{$\mathbf{H}$} \\
\hline Analiz Kriteri & $\mathrm{F}$ & $\mathrm{P}$ & $\mathrm{F}$ & $\mathrm{P}$ & $\mathrm{F}$ & $\mathrm{P}$ & $\mathrm{F}$ & $\mathrm{P}$ & $\mathrm{F}$ & $\mathrm{P}$ & $\mathrm{F}$ & $\mathrm{P}$ & $\mathrm{F}$ & $\mathrm{P}$ \\
\hline Pillai's & 0.543 & 0.76 & 1.525 & 0.356 & 0.622 & 0.713 & 0.503 & 0.784 & 0.623 & 0.712 & 1.045 & 0.507 & 1.592 & 0.34 \\
\hline Önem Derecesi & & & & & & & & & & & & & & \\
\hline
\end{tabular}

\section{Tartıșmalar}

Farklı pale boyu, farklı pim yerleşim senaryoları ve farklı bağlama kuvveti seviyeleri ile yapılan sonlu eleman analizlerinde, öncesinde gerçekleştirilen eleman boyutu hassasiyeti çalışmaları sayesinde herhangi bir tekillik veya sıra dişı değerle karşılaşılmamıştır. Tablo 6'dan da görüleceği üzere palelerin 3Boyutlu (3B) geometrileri üzerindeki deformasyon dağılımını farklı renklerle gösteren sonuç bantları birbirleri arasında dengeli bir geçiş sergilemektedir. Gerçekleştirilen sonlu eleman analizleri sayesinde fikstür tasarım kriterleri açısından önemli bilgilere ulaşılmıştır. Buna göre 13 numaralı deneydeki şartlar sağlandığında en yüksek deformasyon $(0.0974 \mathrm{~mm})$ ve 18 numaralı deneydeki şartlar sağlandığında en düşük deformasyon $(0.0062 \mathrm{~mm})$ seviyesi yakalanmaktadır. Kisa palede uygulanan farklı senaryoların deformasyon ortalaması $0.027456 \mathrm{~mm}$ iken uzun palede uygulanan farklı senaryoların deformasyon ortalaması $0.044189 \mathrm{~mm}$ değerindedir. Bu anlamda, sadece sonlu elemanlar analizlerini dikkate alarak pale boyutlarının deformasyon üzerinde etkili olduğu söylenebilir. Diğer bir faktör olan bağlama kuvvetinin de deformasyon üzerinde etkili olduğu görülmektedir. Buna göre bağlama kuvvetinin $125 \mathrm{~N}$ ile en düşük seviyede uygulandığı deneylerin deformasyon ortalaması da $0.01617 \mathrm{~mm}$ ile en düşük seviyede seyretmektedir. Ulaşılan değerler geçmiş literatür ile karşılaştırıldığında kabul edilebilir seviyelerdedir. Örneğin, havacılıkta kullanılan diğer bir nikel esaslı alaşım olan CMSX-4'ün araştırıldığı ve deneylerle doğrulandığı bir yayında, deformasyon değerlerinin araştırılan etkenler arasında $0.025 \mathrm{~mm}$ ile $0.15 \mathrm{~mm}$ arasında değiştiği görülmektedir [14]. Yine yapılan diğer bir çalışmada, ince cidarlı çelik malzemeden olan bir parçanın bağlama sırasındaki deformasyonları incelenmiş ve değer olarak $0.0246 \mathrm{~mm}$ seviyeleri tespit edilmiştir [15]. Bununla beraber pale boyunun ve bağlama kuvvetinin diğer faktörlerle etkileşimini anlamak adına diğer analiz sonuçlarını da incelemek faydalı olacaktır. Sonlu elemanlar analizleri sonucunda Von-Mises gerilme kriteri dikkate alınarak elde edilen en yüksek eşdeğer gerilme $745 \mathrm{MPa}$ ile 4 numaralı deneyde ve en düşük eşdeğer gerilme ise $210 \mathrm{MPa}$ ile 15 numaralı deneyde elde edilmiştir. Öte yandan deneylerin genelinde hesaplanan gerilme değerlerinin büyük çoğunluğunun Inconel 718 malzemenin akma dayanımından daha düşük olduğu görülmektedir. $\mathrm{Bu}$ sebeple bu gerilmelerin oluşturduğu deformasyonlarda, plastik deformasyon şekil değiştirme oranının düşük olacağı öngörülmektedir. Yine de yanlış bir fikstür tasarımı ve bağlama parametresi ile sabitlenen bir palenin işlemeden önce elastik olarak deforme olmuş olması, takım yolunun gitmesi gereken nominal bölgenin dışını işlemesine neden olacak, ve giriş bölümünde literatür referans alınarak verilen hassasiyetler $( \pm 0.010 \mathrm{~mm})$ elde edilemeyecektir [6].

L18 $\left(2^{1} \times 3^{7}\right)$ ortogonal dizisindeki deney tasarımları esas alınarak yapılan Taguchi hesaplamaları da kendilerinden önce gerçekleştirilen sonlu eleman analizlerini destekler niteliktedir. Şekil 8'de de sunulduğu üzere pale deformasyonuna etkisi en fazla olan 3 faktör sırası ile H (Bağlama kuvveti), A (Pale boyutu) ve C (2. Pimin kendine en yakın pale sınırına uzaklığının pale yüksekliğine oranı) faktörleridir. Salt sonlu eleman analizleri ile önemi tespit edilemeyen $C$ faktörünün Taguchi yöntemi ile tespit edilmiş olması çok değerlidir. Şekil 8'de de görüleceği üzere, C faktörü seviyesinin artışı, yani 2. pimin kendine en yakın pale sınırından uzaklaşması deformasyonun azalmasını etkilemektedir.

Araştırmanın son basamağında çok değişkenli bu durum için varyans analizleri gerçekleştirilmiştir. Pillai analiz kriterine göre yapılan analizlerde A faktörü dışındakilerin kendi arasındaki etkileşimi gözlemlenmiştir. Bunun temel sebebi A faktör seviyesinin diğerlerinden farklı olmasıdır. MANOVA bulguları Tablo 9'da verilmektedir. Tablodaki kolonlarda görülen iki değer arasından "F" değeri MANOVA veya ANOVA analizlerindeki temel istatistiksel değerdir. Bu değer iki veya daha fazla faktörün ortalamasının farklı sonuçları temsil edip etmediğini belirlemek için tüm ortalamaların aynı anda karşılaştırılmasını sağlar. Bir faktörün $F$ değerinin diğer faktörlerden veya varsa FKritik değerinden büyük olması, ilgili faktörün sonuçlar üzerinde kayda değer etkisi olduğunu gösterir. Kabaca F değerinin tersi olarak düşünülebilecek "P" değeri ise sıfir hipotezinin doğru olduğu varsayılarak, deneyde (F) elde edilen kadar büyük bir sonucun (Fkritik) gözlemlenme olasılığıdır. Düşük $\mathrm{P}$ değerleri, sıfır hipotezine karşı güçlü kanıtların göstergeleridir. Tablo 9 aktarılan bilgiler ışı ğında derecelendirilmiş ve pale deformasyonuna etkisi en fazla olan 3 faktör sırası ile H (Bağlama kuvveti), C (2. Pimin kendine en yakın pale sınırına uzaklığının pale yüksekliğine oranı) ve G (3. Pimin kendine en yakın pale sınırına uzaklığının pale genişliğine) olarak tespit edilmiştir. Burada A faktörü olmadığı için sıralamada yer almamıştır.

\section{Sonuçlar}

Bu çalışmada hassas ve maliyetli olan kompresör ve türbin palelerinin fikstür tasarımlarının sistematik analizleri gerçekleştirilmiştir. $\mathrm{Bu}$ kapsamda güncel uçak motorları ile uyumlu ölçülere sahip iki adet pale geometrisi oluşturulmuş ve bu 
paleleri sabitleyen pimlerin yerleşimleri ile bağlama kuvvetlerini dikkate alan, Taguchi yöntemi ile uyumlu deney tasarımları planlanmıştır. Deney tasarımında planlanan farklı senaryolar Inconel 718 malzeme için sonlu elemanlar yöntemi ile incelenmiş ve sonuçlar üzerinde çok değişkenli varyans analizleri (MANOVA) yapılmıştır. Ulaşılan sonuçlar aşağıda özetlenmektedir.

- Bağlama kuvvetleri palelerde görülen deformasyonlarda önemli etkiye sahiptir. Bu durum hem sonlu eleman analizleri, hem Taguchi hesaplamaları hem de MANOVA ile tespit edilmiştir.

- Deformasyonlara etkisi açısından önemli diğer bir faktör ise pale boyutlarıdır. Benzer fikstür tasarım metodolojisi ve bağlama kuvvetlerinin uygulandığı durumda, pale boyutundaki artış toplam deformasyona yansımaktadır.

- 3-2-1 kuralına göre tasarlanan ve pale akış yüzeylerine yerleştirilen üç pim arasından deformasyonda en etkili olanı pale ucuna yakın pimdir. Söz konusu pimin pale köküne doğru yaklaştırılması deformasyonları azaltıcı yönde olumlu etki yapmaktadır.

- Pale genişliği boyunca yerleşimi açısından en etkili pim ise pale akış yüzeylerine yerleştirilen üç pim arasından orta bölgede bulunandir.

\section{Teşekkür}

Bu çalışma, TUBİTAK 2209-A - Üniversite Öğrencileri Araştırma Projeleri Destekleme Programı altında ve Eskişehir Teknik Üniversitesi Bilimsel Araştırma Proje destekleri kapsamında 209 programı altında 21LTP026 proje numarası ve "Kompresör ve Türbin Palelerinin İşlenmesine Yönelik Fikstür Tasarım Metodolojisi Geliştirilmesi” adı ile desteklenen proje dahilinde yapılmıştır.

\section{Kaynakça}

1. Saraçyakupoğlu, T. (2021). Bir Gaz Türbin Motoru Kompresör PalesininTi6Al4V Alaşımından Eklemeli Üretim Yöntemi ile İmalatı ve Boyutsal Doğrulaması. Mühendis ve Makina, 62(702), 151-179.

2. Poyraz, Ö., Yilmaz, O., \& Yasa, E. (2014, June). Investigation of Free-Form Surface Reconstruction Techniques for Reverse Engineering of Worn-Out Gas Turbine Blades: A Case Study. In The 16th International Conference on Machine Design and Production (Vol. 30).

3. Mevissen, F., \& Meo, M. (2019). A review of NDT/structural health monitoring techniques for hot gas components in gas turbines. Sensors, 19(3), 711.

4. Naumann, H. G. (1982). Steam turbine blade design options: how to specify or upgrade. In Proceedings of the 11th Turbomachinery Symposium. Texas A\&M University. Turbomachinery Laboratories.

5. Poyraz, Ö., Ozaner, O.C., \& Subaşı, L. (2019). Comparative review on the manufacturing of turbine blade fir-tree roots. In Proceedings of UTIS 10th International Congress on Machining.

6. Moneta, G., Jachimowicz, J., \& Osiński, J. (2015). Influence of Manufacturing Tolerances on Vibration Frequencies of Turbine Blade. Machine Dynamics Research, 38(1).

7. Gameros, A., Lowth, S., Axinte, D., Nagy-Sochacki, A., Craig, O., \& Siller, H. R. (2017). State-of-the-art in fixture systems for the manufacture and assembly of rigid components: A review. International Journal of Machine Tools and Manufacture, 123, 1-21.

8. Snigdha, M., Sandeep, S.C., Swathi, G., Suresh, R., \& Hanuma, P. (2017). Design of Fixture for the Manufacturing of Compressor Rotor Blade in Aircraft Engine. International Journal of Mechanical Engineering and Technology (IJMET), Vol 8, pp. 1034-1051.

9. Wang, H., Huang, L., Yao, C., Kou, M., Wang, W., Huang, B., \& Zheng, W. (2015). Integrated analysis method of thinwalled turbine blade precise machining. International Journal of Precision Engineering and Manufacturing, 16(5), 10111019.

10. Dwyer, J. P. (2001). U.S. Patent No. 6,186,867. Washington, DC: U.S. Patent and Trademark Office.

11. ASME. (2009). Dimensioning, \& Tolerancing, Y14. 5-2009. NY: The American Society of Mechanical Engineers.

12. Flack, D. R., \& Hannaford, J. (2006). Fundamental good practice in dimensional metrology.

13. Wu, D., Wang, H., Peng, J., Zhang, K., Yu, J., Zheng, X., \& Chen, Y. (2020). Machining fixture for adaptive CNC machining process of near-net-shaped jet engine blade. Chinese Journal of Aeronautics, 33(4), 1311-1328.

14. Wang, Y., Hodgson, A., Chen, X., \& Gindy, N. (2008). A methodology for the development of machining fixtures for components with complicated geometry. International Journal of Computer Integrated Manufacturing, 21(7), 848856.

15. RadhaMadhavi, C., Ramu, B., \& Srinivasulu, K. (2014). Design of machining fixture for turbine rotor blade. International Journal of Research in Engineering and Technology, 3(3), 1-14.

16. Vale, T. D. O., Villar, G. D. C., \& Menezes, J. C. (2012). Methodology for structural integrity analysis of gas turbine blades. Journal of Aerospace Technology and Management, 4(1), 51-59.

17. Huang, Q., Yadav, S., Gao, S., Xu, Z., \& Wang, X. (2018, October). Analysis of Adaptive Clamping Force of Fixture Based on Finite Element Method. In IOP Conference Series: Materials Science and Engineering (Vol. 423, No. 1, p. 012116). IOP Publishing.

18. Wang, H., Zhang, K., Wu, D., Yu, T., Yu, J., \& Liao, Y. (2021). Analysis and optimization of the machining fixture system stiffness for near-net-shaped aero-engine blade. The International Journal of Advanced Manufacturing Technology, 113(11), 3509-3523.

19. Maloney, P., Moroz, N., Stanfill, C., \& Zalenski, N. (2008). Turbine Blade Fixture for Inspection and Grinding. no. April.

20. Chavan, S.G., \& Karidkar, S.S. (2012). Experimental Stress Analysis In A Fixture System Using, FEA. International Journal of Engineering Research \& Technology (IJERT), Vol. 1 Issue 10.

21. Chen, W., Ni, L., \& Xue, J. (2008). Deformation control through fixture layout design and clamping force optimization. The International Journal of Advanced Manufacturing Technology, 38(9-10), 860.

22. Qing, M. I. A. O., Wenfeng, D. I. N. G., KUANG, W., \& Changyong, Y. A. N. G. (2019). Grinding force and surface quality in creep feed profile grinding of turbine blade root of nickel-based superalloy with microcrystalline alumina abrasive wheels. Chinese Journal of Aeronautics.

23. Raffles, M. H., Kolluru, K., Axinte, D., \& Llewellyn-Powell, H. (2013). Assessment of adhesive fixture system under static and dynamic loading conditions. Proceedings of the 
Institution of Mechanical Engineers, Part B: Journal of Engineering Manufacture, 227(2), 267-280.

24. Bhaduri, D., Soo, S. L., Aspinwall, D. K., Novovic, D., Harden, P., Bohr, S., \& Martin, D. (2012). A study on ultrasonic assisted creep feed grinding of nickel based superalloys. Procedia CIRP, 1, 359-364.

25. Kumar., D. (2020). Turbofan Engine for Medium-Range Aircraft with take-off thrust $101.46 \mathrm{kN}$. Thesis, 10.13140/RG.2.2.35715.3280. 